\title{
The Effects of Fetal and Childhood Exposure to Antiretroviral Agents
}

Catherine M. Mas, Tracie L. Miller, Christina Cordero, Danielle Dauphin, Marie Boursiquot White, Christie K. Vila, Gabriel Somarriba, James D. Wilkinson and Steven E. Lipshultz*

The Department of Pediatrics, University of Miami Miller School of Medicine, Miami FL, USA

\begin{abstract}
Purpose: The compliant use of combination antiretroviral therapy has virtually eliminated perinatal HIV transmission. Although antiretroviral drug toxicities in adults have been well documented, the effects of fetal and early childhood exposure to antiretroviral drugs on children of HIV-positive mothers are not well known.

Methods: We searched the Pub Med database, reviewed publications, and selected abstracts on the use of antiretroviral agents to prevent HIV transmission and their effects on growth and cardiac endpoints in fetal and postnatal life.

Results: The link between nucleoside analogs and mitochondrial dysfunction is controversial, and the association between in utero antiretroviral exposure and mitochondrial dysfunction in children is unclear. In utero exposure to antiretroviral therapy has effects on the heart, regardless of HIV status, including improved cardiac function but also reduced cardiac mass of unclear future clinical significance. Preterm delivery and impaired somatic growth have been reported in infants exposed to antiretrovirals, but results are inconsistent. In utero exposure has also been associated with below-normal hematologic parameters. In HIV-infected children, cumulative postnatal exposure to antiretroviral agents is associated with metabolic disturbances and an increased risk for cardiovascular disease.

Conclusion: Antiretroviral therapy is effective in preventing perinatal HIV transmission but may be associated with adverse long-term side effects in exposed infants. Further clinical trials and longitudinal monitoring are needed to understand the long-term effects of in utero exposure to antiretroviral agents.
\end{abstract}

Keywords: HIV; Antiretroviral therapy; Highly active antiretroviral therapy; Mitochondrial dysfunction; Cardiomyopathy; Preterm delivery

Abbreviations: HIV: Human Immunodeficiency Virus; ART: Antiretroviral Therapy; HAART: Highly Active Antiretroviral Therapy; NRTI: Nucleoside Reverse Transcriptase Inhibitors; CHAART: Cardiovascular Status of HAART In HIV-Exposed Infants and Children; $\mathrm{P}^{2} \mathrm{C}^{2}$ HIV: Pediatric Pulmonary and Cardiovascular Complications of Vertically Transmitted HIV Infection

\section{Introduction}

With the advent of antiretroviral therapy (ART), the incidence of perinatal HIV-1 transmission has decreased from $20-25 \%$ to less than $2 \%$ [1]. In the developed world, ART prophylaxis during pregnancy is the standard treatment given to HIV-infected pregnant women, subjecting all infants born to HIV-positive mothers to drug toxicity. In the United States (US), this represents about 10,000 HIV-negative children exposed to ART born each year [2]. As the elimination of mother-to-child transmission of HIV becomes a reality, more patients are becoming exposed to antiretrovirals in utero, while long-term effects of these exposures remain unknown.

However, recent studies suggest that exposure to antiretroviral medications may have marked adverse effects, independent of HIV status [3,4]. Nucleoside analogs and protease inhibitors have been linked to mitochondrial toxicity and various metabolic and cardiovascular complications. Since the mid-1990s, highly active ART (HAART), a combination therapy of three or more HIV-suppressing drugs, has significantly improved the immunological status of the infected population, making HIV a manageable illness. Though mothers on HAART regimens may have optimal health, they expose their children to potent drugs and possible toxicity.

The long-term effects of these agents are better understood in HIV-infected adults, who present with the side effects of cumulative antiretroviral exposure. These effects on children have received less attention, partly because many become orphaned or are unaware of their fetal exposure, and partly because of the lack of follow-up after HIV-negative status has been established.

Accordingly, we performed a rapid systematic review of the literature for studies reporting any cardiac or somatic effects on infants and children exposed to these medications in utero and in early life. Although we focus on cardiac and somatic growth effects, other systems may be affected as well. Here, we report the results of our review.

\section{Methods}

We searched Pub Med for articles on the risks of exposure to the antiretroviral drugs used in preventing mother-to-child transmission of HIV. Using a basic Boolean search technique, we used the search terms "antiretroviral therapy" OR "NRTI" OR "protease inhibitor" AND "mitochondrial." We were also interested in the effects that in utero exposure to HAART has on the cardiovascular system and what cardiac effects are present in this population during early childhood, since these are well-known developmental changes associated with drug toxicities. We searched with the terms "HAART" OR

*Corresponding author: Steven E. Lipshultz, MD, Department of Pediatrics (D80), University of Miami Miller School of Medicine P.O. Box 016820 Miami, FL, USA, Tel: 305 243-3993; Fax: 305 243-399; E-mail: slipshultz@med.miami.edu

Received August 05, 2011; Accepted October 17, 2011; Published October 20 2011

Citation: Mas CM, Miller TL, Cordero C, Dauphin D, White MB, et al. (2011) The Effects of Fetal and Childhood Exposure to Antiretroviral Agents. J AIDS Clinic Res S2:001. doi:10.4172/2155-6113.S2-001

Copyright: ( 2011 Mas CM, et al. This is an open-access article distributed under the terms of the Creative Commons Attribution License, which permits unrestricted use, distribution, and reproduction in any medium, provided the original author and source are credit ed. 
"antiretroviral therapy" AND "cardiovascular" OR "cardiac" AND “in utero" OR "fetal." We searched for similar cardiac endpoints using the same strategy.

To determine the effects of in utero exposure on growth, we searched under "HAART" OR "antiretroviral therapy" AND "growth" OR "height" OR "weight" OR "preterm." To compare the outcomes of different strategies given different circumstances for preventing vertical HIV transmission, we used search terms such as "monotherapy" AND "prophylaxis" OR "antiretroviral therapy." We also examined selected published abstracts on this topic.

\section{Results}

\section{Mitochondrial toxicity associated with antiretrovirals}

Prenatal antiretroviral exposure depletes mitochondrial DNA, and nucleoside analogs are the leading cause of antiretroviral mitochondrial toxicity [5-10]. Blanche et al. reported mitochondrial dysfunction in HIV-uninfected children fetally and postnatally exposed to the nucleoside reverse transcriptase inhibitor (NRTI) zidovudine, raising concerns over the growing use of multiple nucleoside analogs in prophylactic ART [7]. Since then, several studies have found that mitochondrial DNA levels were below normal in HIV-uninfected children exposed to antiretroviral agents in utero $[6,11,12]$. Poirier et al. compared HIV-negative infants born to HIV-negative mothers with HIV-negative infants born to HIV-positive mothers who received either no ART or zidovudine while pregnant. This study linked mitochondrial DNA depletion to in utero exposure to zidovudine [11]. Both Blanche et al. and Poirier et al. found that the incidence of mitochondrial dysfunction was higher in HIV-uninfected infants than it is in the general population, and this risk was even higher for children prenatally exposed to multiple NRTIs than it was for infants exposed to zidovudine monotherapy [13].

Data from a more recent study conflict with the above proposition that antiretroviral exposure is linked to mitochondrial dysfunction. These data indicate that mitochondrial DNA depletion is not related to antiretroviral exposure, but rather to HIV exposure [14]. Although mitochondrial DNA levels were lower in ART-exposed infants than in healthy infants, these levels in HIV-exposed but uninfected infants were markedly lower in ART-unexposed infants than they were in ART-exposed infants. In HIV-uninfected children, concentrations of mitochondrial DNA increase to normal in antiretroviral-exposed children after 5 years, but they remain depressed in antiretroviralunexposed children, suggesting that the effect on mitochondrial DNA depletion is more related to HIV exposure [14].

Several animal studies have found that gestational exposure to antiretroviral drugs is clearly associated with mitochondrial toxicity, irrespective of HIV status. Fetal Erythrocebus patas monkeys exposed in utero to daily doses of zidovudine had abnormal mitochondria, decreased mitochondrial DNA levels, and mitochondrial myopathy in cardiac and skeletal muscle cells [15]. The results from another primate model revealed mitochondrial DNA depletion not only in cardiac and skeletal muscle cells of antiretroviral-exposed fetuses, but also in the cerebellum and cerebrum [16]. Studies in mice have also indicated that the heart is the target organ for NRTI-induced mitochondrial damage $[17,18]$. For example, combination zidovudine-lamivudine therapy caused cardiac mitochondrial cell mutations and substantial mitochondrial DNA depletion [17]. A similar mouse study also found that prophylactic NRTI-based regimens cause marked cardiac damage that persisted months after the exposure and increased with combination NRTI-therapy [19].

Another study on cell lines suggests that HAART may exacerbate HIV-associated cardiovascular complications because of antiretroviralinduced endothelial mitochondrial dysfunction [20]. Additionally, NRTIs may cause mitochondrial mutations. Alterations in the mitochondrial DNA from umbilical cord tissue may explain adverse vascular effects, and combination therapy results in more frequent mutations [21].

NRTIs similarly deplete mitochondria in adipose tissue, which may adversely affect mitochondrial metabolism, causing lipid disorders such as lipodystrophy, lipoatrophy, and diabetes [22-24]. Some HIV protease inhibitors potentially induce oxidative stress, alter mitochondrial function, and alter glucose metabolism [2528]. Researchers examining protease inhibitors in animal models for their effect on glucose homeostasis found that some do target glucose transporter-4 [29]. In rodent models, ritonavir, indinavir, and lopinavir cause impaired glucose transport, and ritonavir inhibits glucose transport to the myocardium [29-31]. A study on healthy human volunteers has associated protease inhibitors with adverse metabolic effects [32]. Although most of the clinical data are from adults, impaired glucose tolerance has been detected in HIV-infected children on long-term HAART regimens [33-35]. Protease inhibitor therapy may lead to insulin resistance in children by impairing the $\beta$-cell response to insulin sensitivity [33].

\section{Antiretroviral agents and cardiac end points}

The long-term cardiac effects of in utero exposure to HAART have not been well studied. Although several studies have noted the increased prevalence of cardiovascular diseases and left ventricular dysfunction in HIV-infected persons, they could not conclusively attribute these conditions to ART $[36,37]$. In early studies of HIV-infected patients not treated with HAART, cardiac complications have been associated with lower CD4+ cell counts, myocarditis, and poor nutritional status [3840]. However, recent evidence has independently linked in utero multiagent ART exposure to impaired cardiac structure and growth during gestation and early life [3,41-43]. The results of the National Heart, Lung, and Blood Institute (NHLBI) Cardiovascular Status of HAART in HIV-Exposed Infants and Children (CHAART-I) cohort study show that in utero exposure to multi-agent ART improved left ventricular systolic function, but cardiac growth parameters were below normal. In HIV-exposed but uninfected infants, septal thickness, left ventricular mass, and left ventricular dimension during the first 2 years of life were lower in ART-exposed infants compared to ART-unexposed infants [3].

\section{Cardiac effects in HIV-uninfected children}

The NHLBI Pediatric Pulmonary and Cardiovascular Complications of Vertically Transmitted HIV Infection $\left(\mathrm{P}^{2} \mathrm{C}^{2} \mathrm{HIV}\right)$ study, which followed patients in the pre-HAART era, suggested that fetal exposure to HIV infection, associated disease factors, and other health habits increased the risk of cardiovascular complications, but single-agent ART prophylaxis had no adverse effect [44]. The $\mathrm{P}^{2} \mathrm{C}^{2}$ HIV study found a high prevalence of cardiac abnormalities and left ventricular dysfunction associated with HIV infection, but it did not find any statistically significant differences between children exposed to zidovudine and those not exposed [44-46]. The NHLBI CHAART-I study compared HIV-uninfected and ART-unexposed infants from the $\mathrm{P}^{2} \mathrm{C}^{2} \mathrm{HIV}$ study with $\mathrm{HIV}$-uninfected and multi-agent ART- 
exposed infants. The results showed that in utero ART exposure is independently associated with cardiac abnormalities [3]. Although multi-agent ART exposure is associated with improved left ventricular contractility and fractional shortening in the first 2 years of life, left ventricular function is still below normal during this same time. Multiagent ART appears to inhibit myocardial growth, which may cause progressive left ventricular dysfunction. Girls were more sensitive to these cardiac effects, a finding that confirms results from a rodent study revealing the increased vulnerability of female mice to zidovudine exposure compared to males [17]. These early effects may predict early and advanced cardiovascular disease (Figure 1).

The Pediatric HIV/AIDS Cohort Study's Surveillance Monitoring of ART Toxicities (SMARTT) protocol is a prospective study supported by the National Institute of Child Health and Human Development (NICHD) that follows HIV-uninfected infants and children exposed to ART. Echocardiograms from this study showed that the hearts of ARTexposed children have marked structural differences that were not observed in unexposed children during the first trimester of pregnancy [41]. Data suggest that in utero abacavir exposure is associated with decreased left ventricular dimension, nevirapine with increased left ventricular wall thickness, and nelfinavir with lower aortic valve diameter, reduced left ventricular wall thickness, and more left ventricular remodeling 4 years after birth [41]. Antiretroviral agents probably induce cardiac toxicity because several studies have indicated that the heart is a target organ of NRTI-associated mitochondrial DNA depletion and alteration, which may explain the impaired cardiac growth in both the CHAART-I and SMARTT studies [17,19,47].

The link between abacavir and an increased risk for cardiovascular disease is still unclear. A meta-analysis of 26 randomized controlled trials with minimized selection bias conducted by the US Food and Drug Administration (FDA) showed no association between abacavir and myocardial infarction in adults [48]. The data from a recent Veterans Affairs observational study of 11,000 patients who were mostly men contrasts the FDA study, as they suggest an increased risk
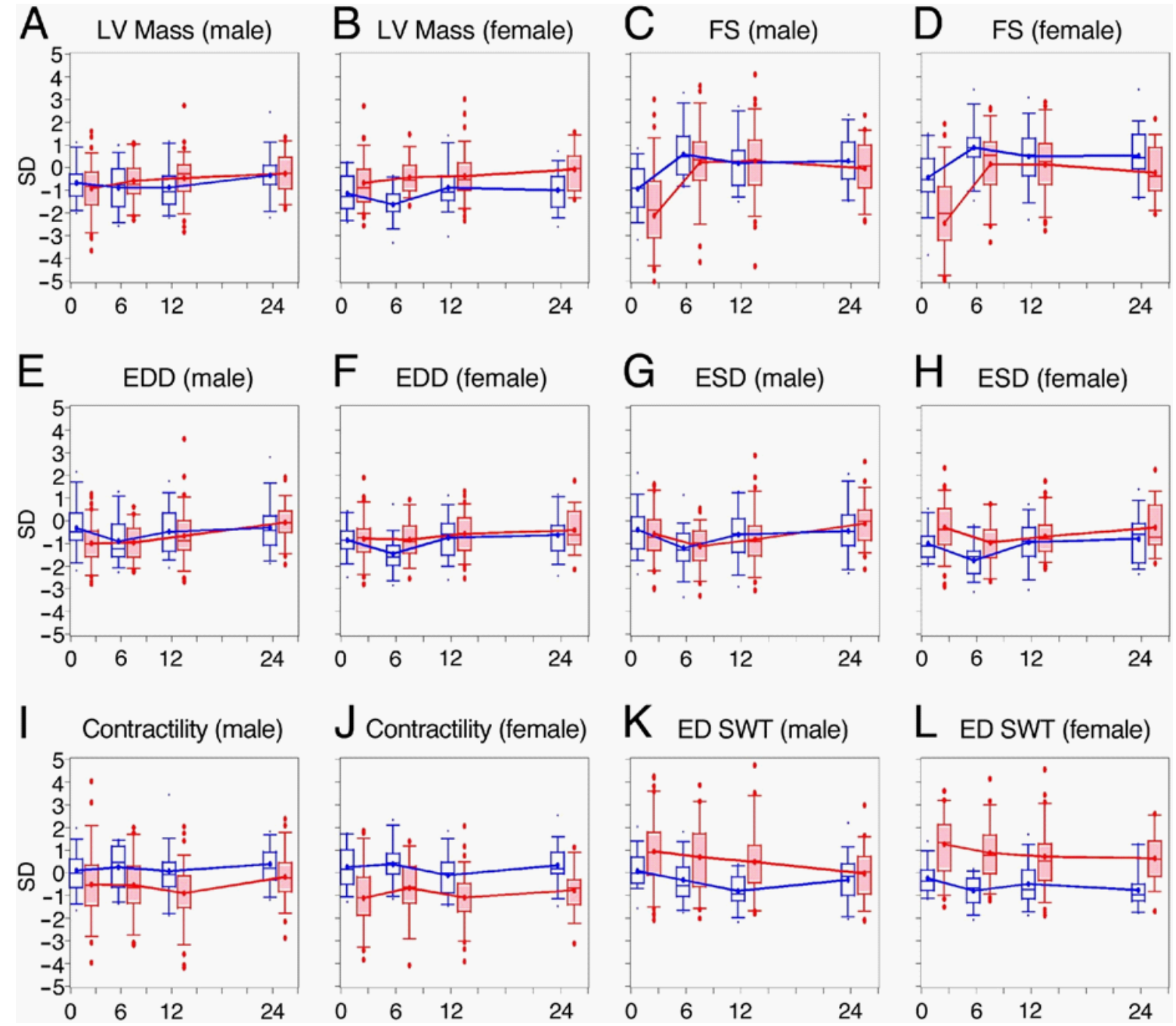

Figure 1: Cardiac Measurements of $136 \mathrm{CHAART}-\mathrm{I}$ Infants and $216 \mathrm{P}^{2} \mathrm{C}^{2} \mathrm{HIV}$ Infants.

Data from antiretroviral therapy (ART)-positive infants in the CHAART-I study are shown by the blue line with open boxes. Data from ART-negative infants in the $\mathrm{P}^{2} \mathrm{C}^{2}$ HIV study are shown by the red line with solid boxes. Rectangles show interquartile ranges, and vertical lines show the 5th percentile to the 95 th percentile. Dots represent outliers. EDD = end-diastolic dimension; ED SWT = end-diastolic septal wall thickness; ESD = end-systolic dimension; FS = fractional shortening; $\mathrm{LV}=$ left ventricular. 
for cardiovascular events in patients exposed to abacavir [49]. However, the original Veterans Affairs study of 19,000 abacavir-treated patients did not show increased risk for myocardial infarction, but it did show that abacavir was associated with reduced risk for cerebrovascular events [50]. Additionally, a recently published Danish study found that abacavir was associated with an increased risk for cerebrovascular events, and it was the only antiretroviral studied to show any association with cerebrovascular risk [51]. These studies provide conflicting results, warranting further screening for cardiovascular and cerebrovascular disease in patients exposed to abacavir.

HIV-uninfected infants exposed to ART in utero also exhibit lower-than-normal platelet, total lymphocyte, CD4+, and CD8+ cell counts that persisted through the first 2 years of life [52]. These infants also have marked anemia and neutropenia in the first 3 months of life, and hematologic values were more severely altered with increasing intensity of the maternal ART regimen [53]. Further data suggest that transplacental zidovudine exposure is associated with genotoxicity [54]. The long-term clinical implications of these low hematologic values, as well as reduced myocardial mass and structural abnormalities are unknown and thus necessitate long-term follow up of infants born to HIV-infected mothers, regardless of HIV status.

\section{Cardiac effects in HIV-infected children}

The NHLBI CHAART-II study of HIV-infected children born in the HAART era reported results similar to those found in HIVuninfected multi-agent ART-exposed infants. Those exposed to multiagent ART had markedly lower intracardiac septal thickness, left ventricular mass, dimension, and afterload and higher left ventricular fractional shortening and contractility than those of unexposed HIV-infected children [42]. The Adolescent Master Protocol (AMP), another sub-study of the Pediatric HIV/AIDS Cohort Study, follows HIV-infected adolescents and pre-adolescents who have received ART since fetal life. AMP has reported increased cardiovascular risk in these adolescents and has suggested that exposure to multi-agent ART is associated with long-term adverse cardiac effects. Children treated with long-term HAART had alterations in left ventricular dimension, left ventricular ejection fraction, and increased aortic valve dimension compared to HIV-uninfected controls, and HAART-exposed children with higher viral loads and the presence of non-cardiac HIV symptoms had increased aortic valve dimensions [55].

Miller et al. found that elevated biomarkers of vascular dysfunction in HIV-infected children were more related to HIV disease severity than antiretroviral exposure [56]. A high rate of coronary artery abnormalities in HIV-infected children has also been reported and is probably a result of early plaque development, suggesting an increased risk of atherosclerosis [57]. As noted previously, the link between abacavir exposure and cardiovascular disease is unclear. Combination ART regimens may adversely affect vascular structure and function [58]. The results of a Canadian study comparing 7,053 HIV-positive adults with 27,681 HIV-negative adults showed that any exposure to abacavir, efavirenz, lopinavir, or ritonavir caused a marked increased risk of acute myocardial infarction [59]. This study demonstrated that each of the commonly used classes of antiretroviral drugsNRTIs, non-nucleoside reverse transcriptase inhibitors, and protease inhibitors-are associated with increased cardiovascular risk.

Charakida et al. measured carotid intima-media thickness and brachial artery flow-mediated dilation in HIV-infected children, and they found that children on protease inhibitor-based ART had greater carotid intima-media thickness and impaired flow-mediated dilation than children who did not receive a protease inhibitor [60]. Thus, protease inhibitor regimens may increase cardiovascular risk in infected children who already face HIV-related atherosclerotic cardiovascular complications $[44,61]$.

Although cardiovascular disease is associated with HIV infection itself, protease inhibitors and NRTIs cause metabolic disturbances such as insulin resistance, glucose intolerance, dyslipidemia, and the lipodystrophy syndrome, all of which are factors associated with accelerated cardiovascular disease [4,62-67]. Bitnun et al. reported that insulin sensitivity was lower in HIV-infected children treated with protease inhibitors than in protease inhibitor-naïve children, suggesting that protease inhibitor therapy may result in insulin resistance, increasing the risk that treated children would develop type 2 diabetes mellitus [33]. AMP revealed that $12.4 \%$ of HIV-infected children showed insulin resistance, and these children also had better virologic control than the rest of the cohort, suggesting ART impairs insulin sensitivity [68]. Further, switching to a protease inhibitorsparing regimen can reverse this dyslipidemia and other metabolic disturbances and improve high-risk cardiovascular profiles [23,69].

\section{Effects on somatic growth and nutrition}

The uterine environment of HIV-infected mothers may have profound effects on fetal life. HIV-associated inflammation and oxidative stress may adversely affect fetal growth. ART prophylaxis is associated with prematurity and reduced growth, but the results are inconsistent [70-76]. Townsend et al. demonstrated an increased incidence of low birth weight for women on HAART when compared to women on monotherapy, and additionally found that the incidence of premature birth among 3384 mothers treated with HAART was 1.5 times that among 1061 mothers treated with a monotherapy or dual therapy regimen [77].

Protease inhibitors as part of an ART regimen may increase the risk of preterm delivery. Cotter et al. found that prophylactic combination therapy with a protease inhibitor had a higher association with premature birth than did monotherapy or combination therapy without a protease inhibitor [14]. The incidence of low-birth-weight infants was lower in women receiving prophylactic zidovudine monotherapy than it was in uninfected women, whereas women receiving ART with a protease inhibitor had a higher incidence of preterm deliveries [71]. These findings link protease inhibitors to preterm delivery; thus, ART prophylaxis with a protease inhibitor should be used with caution [78]. Another study found no difference in the incidence of preterm births between mothers receiving non-nucleoside reverse transcriptase inhibitor-based or protease inhibitor-based therapies [72]. Patel et al. also found that protease inhibitors were not associated with preterm birth [73].

Low birth weight $(<2500$ grams) and very low birth weight $(<1500$ grams) are often associated with prematurity, although clinicians may classify infants as "small for gestational age." Studies have demonstrated lower birth weights in children born to HIV-infected women. One study reported that infants exposed to protease inhibitorcontaining HAART had a higher risk of low birth weight than infants exposed to zidovudine monotherapy or HAART without a protease inhibitor [79]. More recent data published by Powis et al. indicated that the weight of HAART-exposed infants was below normal at birth but returned to normal during the first 6 months of life [74]. Another study that associated low birth weight with HAART exposure claimed that whether HAART affects growth retardation or is associated with higher rates of premature birth was unclear [80]. In an additional study 
which reported no association between HAART and low birth weight, infants exposed to different multi-ART combinations did not differ markedly from those exposed to different protease inhibitors [81].

HIV infection has long been associated with below average growth parameters [40]. Since the advent of HAART, it is not clear whether antiretroviral agents independently affect growth. One study in the pre-HAART era reported that ART exposure contributes to growth failure in HIV-infected infants [75]. Weight and length were below normal for HIV-infected infants by age 6 months, and those on zidovudine had lower growth parameters [75]. Another study showed that HIV-infected children on HAART had reduced pre-pubertal height and final height, with no difference according to duration or type of HAART regimen [82]. Buchacz et al. reported that HIVinfected children on protease inhibitor therapy had small incremental increases in height and weight and were not likely to achieve target final height [83]. While protease inhibitors may have a positive effect on growth by improving nutrient absorption and metabolism, they have raised concerns regarding potential adverse gastrointestinal side effects and loss of appetite, which may contribute to malnutrition [84]. Musoke et al. reported that, much like the aforementioned study on the effect of protease inhibitors, Ugandan children treated with HAART demonstrated improved weight and height within the first year on the regimen [85]. These results were more evident in children who initiated a HAART regimen at a younger age.

Numerous nutritional deficiencies have been demonstrated in HIV-infected children [86,87]. Vitamin D deficiency is gaining attention, as recent data reveal the prevalence of low bone mineral density in both HIV-infected children and adults [88-90]. Though an association between low bone mineral density and ART has been suggested, current studies show conflicting results [91,92]. Jacobson et al. reported reduced bone mineral density in HIV-infected children and that nevirapine, a non-nucleoside reverse transcriptase inhibitor, had positive effects on bone health [88]. Other studies have shown that tenofovir, an NRTI, markedly reduces bone mineral density [93], while others could not attribute these adverse bone effects to tenofovir exposure [94,95].

HAART has improved the nutritional status of HIV-infected children, ending the popular media image of wasting associated with HIV in the pre-HAART era. Hendricks et al. examined the dietary patterns of HIV-infected men and reported higher than recommended caloric intake and weight gains that contrast the wasting in the preHAART era [96]. With the prevention of opportunistic infections and improved immunologic status made possible by HAART, HIVinfected children now have diets similar to those of healthy children and are likewise just as susceptible to the general trend of childhood obesity [97]. Although HAART has greatly reduced malnutrition, gastrointestinal dysfunction and insulin resistance are still reported nutritional problems in HIV-infected children [86]. HIV-infected children's diet quality must be monitored to prevent added risk to preexisting HIV- and HAART-associated cardiovascular risks.

Glucose metabolic disturbances are common in HAART-treated children. Abnormal lipid profiles and decreased insulin sensitivity independently associated with ART have been reported in recent studies $[24,33,34,67]$. Parakh et al. reported lipodystrophy in Indian children treated with World Health Organization recommended NRTIbased HAART [98]. The antiretroviral agents in HAART regimens are associated with mitochondrial dysfunction in adipocytes, which may be the mechanism for glucose metabolic disorders and abnormal lipid profiles $[24,65,99,100]$. These metabolic abnormalities raise concerns for early and advanced cardiovascular risk due to HAART treatment [4].

\section{Discussion}

The use of ART has vastly improved the longevity and quality of life of HIV-infected individuals and has virtually eliminated perinatal infection. It is currently the optimal treatment for both the health of HIV-infected mothers and the lowest incidence of vertical transmission. Our results suggest that although combination ART prophylaxis has the most success in preventing transmission, antiretroviral agents have effects on fetal and postnatal life, regardless of HIV status. The ultimate clinical importance of these ART effects is unknown. In fact, we may be exchanging one disease for another-HIV for cardiovascular diseasewhich poses important ethical considerations.

In our review of the literature we found that ART exposure was independently associated with reduced intracardiac septal thickness and left ventricular mass and dimension to below-normal measurements [3]. Although these children also had increased left ventricular contractility and fractional shortening within the first 2 years of life, this was thought to further contribute to the reduced left ventricular mass [3]. In other studies, these changes in left ventricular structure have been shown to lead to progressive cardiac dysfunction, which causes concern that this may be going unnoticed in the ARTexposed child without proper follow-up [101-103].

In the pre-HAART era, zidovudine prophylaxis had no cardiac effect on exposed infants [45], but studies have shown that more complex prophylactic regimens result in reduced cardiac growth. Though animal models have demonstrated antiretroviral-induced mitochondrial damage and cardiotoxicity, it is unknown if these cardiac effects in humans are related to ART-associated mitochondrial dysfunction. The recent findings that multi-agent ART inhibits myocardial growth confirm the results of previous animal studies [3,19,47]. HIV-infected children face greater risk of cardiac morbidity and mortality as a result of increased left ventricular mass and decreased fractional shortening related to the HIV virus [104], although recent data suggests adverse cardiac effects may be related to ART exposure [3] (Figure 2).

Other abnormalities in ART-exposed, HIV-negative children include anemia, neutropenia, thrombocytopenia, lower CD4 and CD8 T-lymphocyte counts, and increased micronucleated erythrocytes [5254]. Fetal HAART-exposure, in particular, is associated with markedly lower hemoglobin levels and significant anemia [53]. Conflicting data have been reported on the effect of ART on prematurity and birth weight, and further evaluations are needed to determine the root causes of HIV-related birth complications. In HIV-infected children, longterm HAART-exposure is associated with marked metabolic disorders $[23,35,62,67]$.

Depending on worldwide access to antiretroviral drugs, HIVinfected mothers have received diverse regimens to prevent vertical transmission. In resource-limited settings, a single-agent regimen is widely used because access to multi-agent ART is limited. For example, single-agent nevirapine is a common treatment for HIVpositive pregnant women in Africa, and it effectively reduces perinatal transmission [105]. Single-dose nevirapine added to zidovudine prophylaxis further reduces transmission in resource-limited settings [106]. The Six Week Extended Dose Nevirapine study found that the transmission rate for single-dose prophylactic nevirapine was $10.4 \%$, whereas that for extended-dose was $8.9 \%$ [107]. Thus, there is little difference in transmission rates, and single-dose prophylactic 
Citation: Mas CM, Miller TL, Cordero C, Dauphin D, White MB, et al. (2011) The Effects of Fetal and Childhood Exposure to Antiretroviral Agents. J AIDS

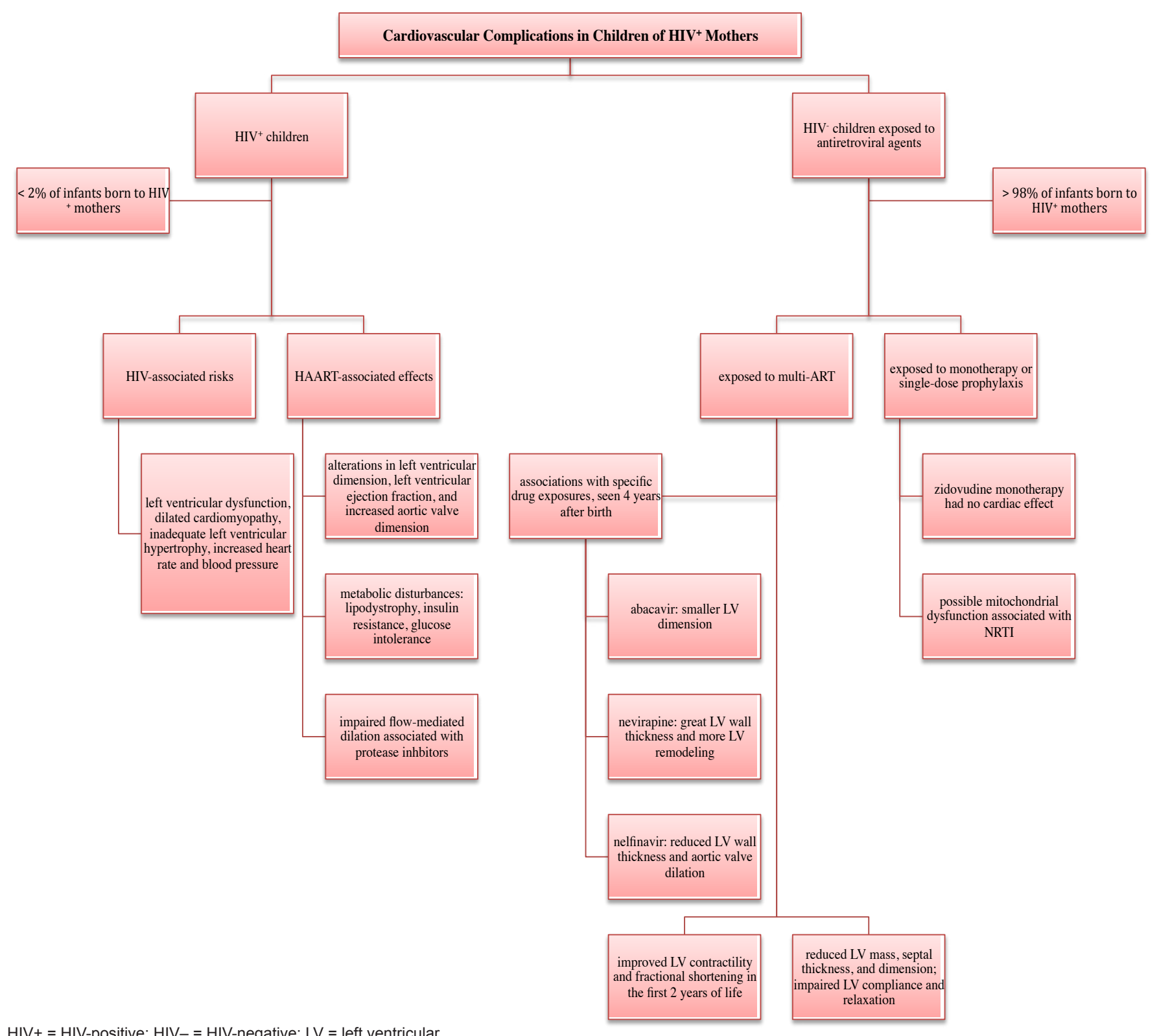

Figure 2: Cardiovascular Complications in Children of HIV-Positive Mothers.

nevirapine is less harmful to HIV-uninfected infants than is an extended-dose regimen [107]. The complexity and duration of regimens may determine the level of mitochondrial toxicity. In a study of HIV-uninfected children exposed in utero and perinatally to NRTIbased multi-agent ART, about half of the subjects developed benign hyperlactatemia [108], whereas in Cote d'Ivoire, the prevalence of hyperlactatemia was $13 \%$ in HIV-uninfected children of mothers who received short duration antiretroviral prophylaxis or single-dose nevirapine [109]. Since lactic acidosis is a reported result of NRTIinduced mitochondrial dysfunction [110], these findings suggest that longer duration multi-agent ART prophylaxis may cause increased mitochondrial toxicity.

The US President's Emergency Plan for AIDS Relief has reported the effectiveness of treating HIV-infected pregnant women with single-dose nevirapine to avert $84 \%$ of new infections in Sub-Saharan Africa [111]. With a $\$ 48$ billion budget, the US will provide more combination ART abroad to report even lower vertical transmission rates in 2011, but will expose an increasing number of infants to potent drugs [111,112]. Although less-complex prophylactic regimens present lower adverse mitochondrial risks, the success of three-drug ART prophylaxis currently demands attention. Ciaranello et al. concluded that in Sub-Saharan Africa, multi-agent ART should be used when available because the risk of mitochondrial toxicity is at least an order of magnitude lower than the risk of HIV infection associated with less-effective regimens [113]. To date, the known benefits of ART prophylaxis outweigh the unknown long-term risks of drug toxicity from fetal exposure. 
With the increased cardiac, growth, and nutritional risks associated with ART have come additional concerns about potential carcinogenicity [114,115]. As a result, monitoring these patients long term will be necessary to understand the clinical implications and the mechanism of ART toxicity. The 2010 National Institutes of Health guidelines recommend that the follow-up of HIV-uninfected children exposed to ART should be extended beyond the current period of 18 months after birth [116]. The effects of in utero exposure to ART are reminiscent of the delayed effects of anthracyclines on childhood cancer survivors. Collaborations between oncologists and cardiologists in longitudinal studies on drug toxicities have greatly increased awareness of anthracyclines' adverse cardiac effects and the discovery that the iron chelator dexrazoxane could reduce long-term damage [117]. A similar collaboration between clinicians of different sub-specialties and researchers could benefit the increasing number of infants and children exposed to ART early in life.

\section{Limitations of the review}

We selected studies to examine based on their relevance to our specific interests and background-cardiac and growth parameters. Given our narrow focus, this review does not address the full scope of beneficial or adverse pharmacological effects of antiretrovirals in children. It is also possible that we overlooked studies published in journals that were not available on Pub Med.

Furthermore, although we reviewed enough studies to justify a conclusion, not enough longitudinal clinical trials have been conducted on HIV-uninfected children born to HIV-infected mothers. For example, the clinical importance of the findings from the CHAART and $\mathrm{P}^{2} \mathrm{C}^{2} \mathrm{HIV}$ studies cannot be determined since there are no existing studies on the effects of HIV and ART exposure on clinically-significant cardiac endpoints to corroborate recent findings. Current ongoing studies, such as the CHAART and Pediatric HIV/AIDS Cohort studies, have collected additional data that have not yet been published, and thus were not included in our review.

\section{Conclusions}

Although ART is presently the most effective treatment for reducing vertical HIV transmission, ART medications may have longterm adverse cardiovascular effects. The growing population of children who were only exposed to ART in utero prompts more rigorous and systematic follow-up. General pediatricians should consider evaluating cardiovascular risk in patients with any past exposure to HIV or ART. HIV-infected children who face cumulative toxicity from HAART should receive complete metabolic screens and lifestyle interventions to modify these risks.

Additionally, the standard treatment of ART prophylaxis without an option for HIV-positive mothers does not allow for a clear assessment of the benefits of a less complex prophylactic regimen. To determine the best treatment for both the mother and child, it may be useful to conduct clinical trials giving pregnant women the choice of a single-agent prophylaxis or of conventional ART prophylaxis. Further long-term prospective clinical trials are needed to understand the side effects of in utero exposure to antiretroviral agents and, in particular, to clarify the mechanism of ART-related mitochondrial dysfunction and cardiomyopathy.

\section{References}

1. Cooper ER, Charurat M, Mofenson L, Hanson IC, Pitt J, et al. (2002) Combination antiretroviral strategies for the treatment of pregnant HIV-1- infected women and prevention of perinatal HIV-1 transmission. J Acquir Immune Defic Syndr 29: 484-494.

2. Suksomboon N, Poolsup N, Ket-Aim S (2007) Systematic review of the efficacy of antiretroviral therapies for reducing the risk of mother-to-child transmission of HIV infection. J Clin Pharm Ther 32: 293-311.

3. Lipshultz SE, Shearer WT, Thompson B, Rich KC, Cheng I, et al. (2011) Cardiac effects of antiretroviral therapy in HIV-negative infants born to HIVpositive mothers: NHLBI CHAART-1 (National Heart, Lung, and Blood Institute Cardiovascular Status of HAART Therapy in HIV-Exposed Infants and Children cohort study). J Am Coll Cardiol 57: 76-85.

4. Miller TL, Orav EJ, Lipshultz SE, Arheart KL, Duggan C, et al. (2008) Risk factors for cardiovascular disease in children infected with human immunodeficiency virus-1. J Pediatr 153: 491-497.

5. Foster C, Lyall H (2008) HIV and mitochondrial toxicity in children. J Antimicrob Chemother 61: 8-12.

6. Walker UA, Setzer B, Venhoff N (2002) Increased long-term mitochondria toxicity in combinations of nucleoside analogue reverse-transcriptase inhibitors. AIDS 16: 2165-2173.

7. Blanche S, Tardieu M, Rustin P, Slama A, Barret B, et al. (1999) Persistent mitochondrial dysfunction and perinatal exposure to antiretroviral nucleoside analogues. Lancet 354: 1084-1089.

8. Brogly SB, Ylitalo N, Mofenson LM, Oleske J, Van Dyke R, et al. (2007) In utero nucleoside reverse transcriptase inhibitor exposure and signs of possible mitochondrial dysfunction in HIV-uninfected children. AIDS 21: 929-938.

9. Crain MJ, Chernoff MC, Oleske JM, Brogly SB, Malee KM, et al. (2010) Possible mitochondrial dysfunction and its association with antiretroviral therapy use in children perinatally infected with HIV. J Infect Dis 202: 291-301.

10. Shiramizu B, Shikuma KM, Kamemoto L, Gerschenson M, Erdem G, et al (2003) Placenta and cord blood mitochondrial DNA toxicity in HIV-infected women receiving nucleoside reverse transcriptase inhibitors during pregnancy. J Acquir Immune Defic Syndr 32: 370-374

11. Poirier MC, Divi RL, Al-Harthi L, Olivero OA, Nguyen V, et al. (2003) Long-term mitochondrial toxicity in HIV-uninfected infants born to HIV-infected mothers. J Acquir Immune Defic Syndr 33: 175-183.

12. Walker VE, Poirier MC (2007) Special issue on health risks of perinatal exposure to nucleoside reverse transcriptase inhibitors. Environ Mol Mutagen 48: 159-165.

13. Barret B, Tardieu M, Rustin P, Lacroix C, Chabrol B, et al. (2003) Persistent mitochondrial dysfunction in HIV-1-exposed but uninfected infants: clinical screening in a large prospective cohort. AIDS 17: 1769-1785.

14. Aldrovandi GM, Chu C, Shearer WT, Li D, Walter J, et al. (2009) Antiretrovira exposure and lymphocyte mtDNA content among uninfected infants of HIV-1infected women. Pediatrics 124: e1189-1197.

15. Gerschenson M, Erhart SW, Paik CY, St Claire MC, Nagashima K, et al. (2000) Fetal mitochondrial heart and skeletal muscle damage in Erythrocebus patas monkeys exposed in utero to 3'-azido-3'-deoxythymidine. AIDS Res Hum Retroviruses 16: 635-644.

16. Gerschenson M, Nguyen V, Ewings EL, Ceresa A, Shaw JA, et al. (2004) Mitochondrial toxicity in fetal Erythrocebus patas monkeys exposed transplacentally to zidovudine plus lamivudine. AIDS Res Hum Retroviruses 20: $91-100$.

17. Chan SS, Santos JH, Meyer JN, Mandavilli BS, Cook DL, Jr., et al (2007) Mitochondrial toxicity in hearts of CD-1 mice following perinatal exposure to AZT, 3TC, or AZT/3TC in combination. Environ Mol Mutagen 48: 190-200.

18. Walker DM, Poirier MC, Campen MJ, Cook DL, Jr., Divi RL, et al. (2004) Persistence of mitochondrial toxicity in hearts of female B6C3F1 mice exposed in utero to 3'-azido-3'-deoxythymidine. Cardiovasc Toxicol 4: 133-153.

19. Torres SM, March TH, Carter MM, McCash CL, Seilkop SK, et al. (2010) In utero exposure of female CD-1 Mice to AZT and/or 3TC: I. Persistence of microscopic lesions in cardiac tissue. Cardiovasc Toxicol 10: 37-50.

20. Hebert VY, Crenshaw BL, Romanoff RL, Ekshyyan VP, Dugas TR (2004) Effects of HIV drug combinations on endothelin-1 and vascular cell proliferation. Cardiovasc Toxicol 4: 117-131.

21. Torres SM, Walker DM, McCash CL, Carter MM, Ming J, et al. (2009) Mutationa analysis of the mitochondrial tRNA genes and flanking regions in umbilical cord 
tissue from uninfected infants receiving AZT-based therapies for prophylaxis of HIV-1. Environ Mol Mutagen 50: 10-26.

22. Beregszaszi M, Dollfus C, Levine M, Faye A, Deghmoun S, et al. (2005) Longitudinal evaluation and risk factors of lipodystrophy and associated metabolic changes in HIV-infected children. J Acquir Immune Defic Syndr 40: 161-168.

23. Vigano A, Brambilla P, Pattarino G, Stucchi S, Fasan S, et al. (2009) Long-term evaluation of glucose homeostasis in a cohort of HAART-treated HIV-infected children: a longitudinal, observational cohort study. Clin Drug Investig 29: $101-$ 109.

24. Mallon PW, Unemori P, Sedwell R, Morey A, Rafferty M, et al. (2005) In vivo, nucleoside reverse-transcriptase inhibitors alter expression of both mitochondrial and lipid metabolism genes in the absence of depletion of mitochondrial DNA. J Infect Dis 191: 1686-1696.

25. Masia M, Padilla S, Bernal E, Almenar MV, Molina J, et al. (2007) Influence of antiretroviral therapy on oxidative stress and cardiovascular risk: a prospective cross-sectional study in HIV-infected patients. Clin Ther 29: 1448-1455.

26. Lagathu C, Eustace B, Prot M, Frantz D, Gu Y, et al. (2007) Some HIV antiretrovirals increase oxidative stress and alter chemokine, cytokine or adiponectin production in human adipocytes and macrophages. Antivir Ther 12: $489-500$

27. Ben-Romano R, Rudich A, Etzion S, Potashnik R, Kagan E, et al. (2006) Nelfinavir induces adipocyte insulin resistance through the induction of oxidative stress: differential protective effect of antioxidant agents. Antivir Ther 11: 1051-1060

28. Carr A, Samaras K, Chisholm DJ, Cooper DA (1998) Pathogenesis of HIV1-protease inhibitor-associated peripheral lipodystrophy, hyperlipidaemia, and insulin resistance. Lancet 351: 1881-1883.

29. Hruz PW, Yan Q, Struthers H, Jay PY (2008) HIV protease inhibitors that block GLUT4 precipitate acute, decompensated heart failure in a mouse model of dilated cardiomyopathy. FASEB J 22: 2161-2167.

30. Hruz PW, Murata H, Qiu H, Mueckler M (2002) Indinavir induces acute and reversible peripheral insulin resistance in rats. Diabetes 51: 937-942.

31. Yan Q, Hruz PW (2005) Direct comparison of the acute in vivo effects of HIV protease inhibitors on peripheral glucose disposal. J Acquir Immune Defic Syndr 40: 398-403.

32. Noor MA, Seneviratne T, Aweeka FT, Lo JC, Schwarz JM, et al. (2002) Indinavir acutely inhibits insulin-stimulated glucose disposal in humans: a randomized, placebo-controlled study. AIDS 16: F1-8.

33. Bitnun A, Sochett E, Dick PT, To T, Jefferies C, et al. (2005) Insulin sensitivity and beta-cell function in protease inhibitor-treated and -naive human immunodeficiency virus-infected children. J Clin Endocrinol Metab 90: 168-174.

34. Murata H, Hruz PW, Mueckler M (2000) The mechanism of insulin resistance caused by HIV protease inhibitor therapy. J Biol Chem 275: 20251-20254

35. Carr A, Samaras K, Burton S, Law M, Freund J, et al. (1998) A syndrome of peripheral lipodystrophy, hyperlipidaemia and insulin resistance in patients receiving HIV protease inhibitors. AIDS 12: F51-58.

36. Fisher SD, Easley KA, Orav EJ, Colan SD, Kaplan S, et al. (2005) Mild dilated cardiomyopathy and increased left ventricular mass predict mortality: the prospective $\mathrm{P}^{2} \mathrm{C}^{2}$ HIV Multicenter Study. Am Heart J 150: 439-447.

37. Starc TJ, Lipshultz SE, Kaplan S, Easley KA, Bricker JT, et al. (1999) Cardiac complications in children with human immunodeficiency virus infection. Pediatric Pulmonary and Cardiac Complications of Vertically Transmitted HIV Infection ( $\left.\mathrm{P}^{2} \mathrm{C}^{2} \mathrm{HIV}\right)$ Study Group, National Heart, Lung, and Blood Institute. Pediatrics 104: e14.

38. Herskowitz A, Wu TC, Willoughby SB, Vlahov D, Ansari AA, et al. (1994) Myocarditis and cardiotropic viral infection associated with severe left ventricular dysfunction in late-stage infection with human immunodeficiency virus. J Am Coll Cardiol 24: 1025-1032.

39. Barbaro G, Di Lorenzo G, Grisorio B, Barbarini G (1998) Cardiac involvement in the acquired immunodeficiency syndrome: a multicenter clinical-pathological study. Gruppo Italiano per lo Studio Cardiologico dei pazienti affetti da AIDS Investigators. AIDS Res Hum Retroviruses 14: 1071-1077.

40. Miller TL, Evans SJ, Orav EJ, Morris V, McIntosh K, et al. (1993) Growth and body composition in children infected with the human immunodeficiency virus-1. Am J Clin Nutr 57: 588-592.
41. Lipshultz SE (2010) Association of cardiac structure and function with in utero antiretroviral exposure among uninfected children born to HIV-infected mothers in the pediatric HIVIAIDS cohort study. Circulation 122: A16026.

42. Lipshultz SE (2009) Antiretroviral therapy (ART) cardiac effects in HIV-infected children: the multicenter NHLBI cardiac highly active antiretroviral therapy (CHAART-II) study. Circulation 120: S909.

43. Lavigne JE, Shearer WT, Thompson B, Orav EJ, Starc TJ, et al. (2004 Cardiovascular outcomes of pediatric seroreverters perinatally exposed to HAART: design of a longitudinal clinical study. Cardiovasc Toxicol 4: 187-197.

44. Lipshultz SE, Easley KA, Orav EJ, Kaplan S, Starc TJ, et al. (2002) Cardiovascular status of infants and children of women infected with HIV-1 ( $\mathrm{P}^{2} \mathrm{C}^{2} \mathrm{HIV}$ ): a cohort study. Lancet 360: 368-373.

45. Lipshultz SE, Easley KA, Orav EJ, Kaplan S, Starc TJ, et al. (2000) Absence of cardiac toxicity of zidovudine in infants. Pediatric Pulmonary and Cardiac Complications of Vertically Transmitted HIV Infection Study Group. N Engl J Med 343: 759-766.

46. Lipshultz SE, Orav EJ, Sanders SP, Hale AR, McIntosh K, et al. (1992) Cardiac structure and function in children with human immunodeficiency virus infection treated with zidovudine. N Engl J Med 327: 1260-1265

47. Torres SM, Divi RL, Walker DM, McCash CL, Carter MM, et al. (2010) In utero exposure of female CD-1 mice to AZT and/or 3TC: II. Persistence of functional alterations in cardiac tissue. Cardiovasc Toxicol 10: 87-99.

48. Ding X, Andraca-Carrera E, Cooper C, Miele P, Kornegay C, et al. (2011) No association of myocardial infarction with $A B C$ use: an FDA Meta-analysis. $18^{\text {th }}$ Conference on Retroviruses and Opportunistic Infections; February 27-March 2, Boston, MA. Abstract 808.

49. Choi Al, Vittinghoff E, Deeks SG, Weekley CC, Li Y, et al. (2011) Cardiovascula risks associated with abacavir and tenofovir exposure in HIV-infected persons. AIDS 25: 1289-1298.

50. Bedimo RJ, Westfall AO, Drechsler H, Vidiella G, Tebas P (2011) Abacavir use and risk of acute myocardial infarction and cerebrovascular events in the highly active antiretroviral therapy era. Clin Infect Dis 53: 84-91.

51. Rasmussen LD, Engsig FN, Christensen H, Gerstoft J, Kronborg G, et al. (2011) Risk of cerebrovascular events in persons with and without HIV: A Danish nationwide population-based cohort study. AIDS 25:1637-1646.

52. Pacheco SE, McIntosh K, Lu M, Mofenson LM, Diaz C, et al. (2006) Effect of perinatal antiretroviral drug exposure on hematologic values in HIV-uninfected children: An analysis of the women and infants transmission study. J Infect Dis 194: 1089-1097.

53. Feiterna-Sperling C, Weizsaecker K, Buhrer C, Casteleyn S, Loui A, et al (2007) Hematologic effects of maternal antiretroviral therapy and transmission prophylaxis in HIV-1-exposed uninfected newborn infants. J Acquir Immune Defic Syndr 45: 43-51.

54. Witt KL, Cunningham CK, Patterson KB, Kissling GE, Dertinger SD, et al. (2007) Elevated frequencies of micronucleated erythrocytes in infants exposed to zidovudine in utero and postpartum to prevent mother-to-child transmission of HIV. Environ Mol Mutagen 48: 322-329.

55. Lipshultz SE (2009) Increased left ventricular and aortic dimensions in long-term multiagent antiretroviral therapy (ART)-treated HIV-infected children: the $\mathrm{NIH}$ multicenter pediatric HIVIAIDS cohort study (PHACS). Circulation 120: S909.

56. Miller TL, Somarriba G, Orav EJ, Mendez AJ, Neri D, et al. (2010) Biomarkers of vascular dysfunction in children infected with human immunodeficiency virus-1. J Acquir Immune Defic Syndr 55: 182-188.

57. Mikhail IJ, Purdy JB, Dimock DS, Thomas VM, Muldoon NA, et al. (2011) High rate of coronary artery abnormalities in adolescents and young adults infected with human immunodeficiency virus early in life. Pediatr Infect Dis J 30:710-712.

58. Zareba KM, Lavigne JE, Lipshultz SE (2004) Cardiovascular effects of HAART in infants and children of HIV-infected mothers. Cardiovasc Toxicol 4: 271-279.

59. Durand M, Sheehy O, Baril JG, Lelorier J, Tremblay CL (2011) Association between HIV infection, antiretroviral therapy and risk of acute myocardia infarction: a cohort and nested case-control study using Quebec's public health insurance database (RAMQ). J Acquir Immune Defic Syndr 57: 245-253.

60. Charakida M, Donald AE, Green H, Storry C, Clapson M, et al. (2005) Early structural and functional changes of the vasculature in HIV-infected children impact of disease and antiretroviral therapy. Circulation 112: 103-109. 
Citation: Mas CM, Miller TL, Cordero C, Dauphin D, White MB, et al. (2011) The Effects of Fetal and Childhood Exposure to Antiretroviral Agents. J AIDS Clinic Res S2:001. doi:10.4172/2155-6113.S2-001

61. Lipshultz SE, Easley KA, Orav EJ, Kaplan S, Starc TJ, et al. (1998) Left ventricular structure and function in children infected with human immunodeficiency virus: the prospective $\mathrm{P}^{2} \mathrm{C}^{2}$ HIV Multicenter Study. Pediatric Pulmonary and Cardiac Complications of Vertically Transmitted HIV Infection $\left(\mathrm{P}^{2} \mathrm{C}^{2} \mathrm{HIV}\right)$ Study Group. Circulation 97: 1246-1256.

62. Werner ML, Pone MV, Fonseca VM, Chaves CR (2010) Lipodystrophy syndrome and cardiovascular risk factors in children and adolescents infected with HIVIAIDS receiving highly active antiretroviral therapy. J Pediatr (Rio J) 86: $27-32$

63. Shikuma CM, Gerschenson M, Chow D, Libutti DE, Willis JH, et al. (2008) Mitochondrial oxidative phosphorylation protein levels in peripheral blood mononuclear cells correlate with levels in subcutaneous adipose tissue within samples differing by HIV and lipoatrophy status. AIDS Res Hum Retroviruses 24: $1255-1262$

64. McComsey GA, Libutti DE, O'Riordan M, Shelton JM, Storer N, et al. (2008) Mitochondrial RNA and DNA alterations in HIV lipoatrophy are linked to antiretroviral therapy and not to HIV infection. Antivir Ther 13: 715-722.

65. Caron M, Auclair M, Sterlingot H, Kornprobst M, Capeau J (2003) Some HIV protease inhibitors alter lamin A/C maturation and stability, SREBP-1 nuclear localization and adipocyte differentiation. AIDS 17: 2437-2444.

66. Arpadi SM, Cuff PA, Horlick M, Wang J, Kotler DP (2001) Lipodystrophy in HIVinfected children is associated with high viral load and low CD4+-lymphocyte count and CD4+ -lymphocyte percentage at baseline and use of protease inhibitors and stavudine. J Acquir Immune Defic Syndr 27: 30-34.

67. McComsey GA, Leonard E (2004) Metabolic complications of HIV therapy in children. AIDS 18: 1753-1768

68. Geffner M, Jacobson D, Miller T, et al. (2009) Insulin resistance in adolescents with HIV infection. Paper presented at: Pediatric Academic Societies annual meeting; Baltimore, MD.

69. Balasubramanyam A, Coraza I, Smith EO, Scott LW, Patel P, et al. (2011) Combination of niacin and fenofibrate with lifestyle changes improves dyslipidemia and hypoadiponectinemia in HIV patients on antiretroviral therapy: results of "heart positive," a randomized, controlled trial. J Clin Endocrinol Metab 96: 2236-2247.

70. Thorne C, Patel D, Newell ML (2004) Increased risk of adverse pregnancy outcomes in HIV-infected women treated with highly active antiretrovira therapy in Europe. AIDS 18: 2337-2339.

71. Grosch-Woerner I, Puch K, Maier RF, Niehues T, Notheis G, et al. (2008) Increased rate of prematurity associated with antenatal antiretroviral therapy in a German/Austrian cohort of HIV-1-infected women. HIV Med 9: 6-13.

72. Townsend CL, Cortina-Borja M, Peckham CS, Tookey PA (2007) Antiretrovira therapy and premature delivery in diagnosed HIV-infected women in the United Kingdom and Ireland. AIDS 21: 1019-1026.

73. Patel K, Shapiro DE, Brogly SB, Livingston EG, Stek AM, et al. (2010) Prenatal protease inhibitor use and risk of preterm birth among HIV-infected women initiating antiretroviral drugs during pregnancy. J Infect Dis 201: 1035-1044.

74. Powis KM, Smeaton L, Ogwu A, Lockman S, Dryden-Peterson S, et al. (2011) Effects of in utero antiretroviral exposure on longitudinal growth of HIV-exposed uninfected infants in Botswana. J Acquir Immune Defic Syndr 56: 131-138.

75. Miller TL, Easley KA, Zhang W, Orav EJ, Bier DM, et al. (2001) Maternal and infant factors associated with failure to thrive in children with vertically transmitted human immunodeficiency virus-1 infection: the prospective, $\mathrm{P}^{2} \mathrm{C}^{2}$ human immunodeficiency virus multicenter study. Pediatrics 108: 1287-1296.

76. (2000) Combination antiretroviral therapy and duration of pregnancy. AIDS 14: 2913-2920.

77. Townsend C, Schulte J, Thorne C, Dominguez KI, Tookey PA, et al. (2010) Antiretroviral therapy and preterm delivery-a pooled analysis of data from the United States and Europe. BJOG 117: 1399-1410.

78. Cotter AM, Garcia AG, Duthely ML, Luke B, O'Sullivan MJ (2006) Is antiretrovira therapy during pregnancy associated with an increased risk of preterm delivery, low birth weight, or stillbirth? J Infect Dis 193: 1195-1201.

79. Kowalska A, Niemiec T, El Midaoui A, Burkacka E (2003) Effect of antiretroviral therapy on pregnancy outcome in HIV-1 positive women. Med Wieku Rozwoj 7: 459-468.

80. Ekouevi DK, Coffie PA, Becquet R, Tonwe-Gold B, Horo A, et al. (2008)
Antiretroviral therapy in pregnant women with advanced HIV disease and pregnancy outcomes in Abidjan, Cote d'Ivoire. AIDS 22: 1815-1820.

81. Briand N, Mandelbrot L, Le Chenadec J, Tubiana R, Teglas JP, et al. (2009) No relation between in-utero exposure to HAART and intrauterine growth retardation. AIDS 23: 1235-1243.

82. Stagi S, Galli L, Cecchi C, Chiappini E, Losi S, et al. (2010) Final height in patients perinatally infected with the human immunodeficiency virus. Horm Res Paediatr 74: 165-171.

83. Buchacz K, Cervia JS, Lindsey JC, Hughes MD, Seage GR, 3rd, et al. (2001) Impact of protease inhibitor-containing combination antiretroviral therapies on height and weight growth in HIV-infected children. Pediatrics 108: E72.

84. Mueller BU, Sleasman J, Nelson RP, Jr., Smith S, Deutsch PJ, et al. (1998) A phase I/II study of the protease inhibitor indinavir in children with HIV infection. Pediatrics 102: 101-109.

85. Musoke PM, Mudiope P, Barlow-Mosha LN, Ajuna P, Bagenda D, et al. (2010) Growth, immune and viral responses in HIV infected African children receiving highly active antiretroviral therapy: a prospective cohort study. BMC Pediatr 10: 56 .

86. Miller TL (2003) Nutritional aspects of HIV-infected children receiving highly active antiretroviral therapy. AIDS 17 Suppl 1: S130-140.

87. Miller TL, Agostoni C, Duggan C, Guarino A, Manary M, et al. (2008) Gastrointestinal and nutritional complications of human immunodeficiency virus infection. J Pediatr Gastroenterol Nutr 47: 247-253.

88. Jacobson DL (2005) Predictors of bone mineral density in human immunodeficiency virus- 1 infected children. Journal of pediatric gastroenterology and nutrition 41: 339

89. Glesby MJ (2003) Bone disorders in human immunodeficiency virus infection. Clin Infect Dis 37 Suppl 2: S91-95.

90. McDermott AY, Shevitz A, Knox T, Roubenoff R, Kehayias J, et al. (2001) Effect of highly active antiretroviral therapy on fat, lean, and bone mass in HIVseropositive men and women. Am J Clin Nutr 74: 679-686.

91. Arpadi SM, Horlick M, Thornton J, Cuff PA, Wang J, et al. (2002) Bone minera content is lower in prepubertal HIV-infected children. J Acquir Immune Defic Syndr 29: 450-454.

92. Mora S, Sala N, Bricalli D, Zuin G, Chiumello G, et al. (2001) Bone mineral loss through increased bone turnover in HIV-infected children treated with highly active antiretroviral therapy. AIDS 15: 1823-1829.

93. Gallant JE, Staszewski S, Pozniak AL, DeJesus E, Suleiman JM, et al. (2004 Efficacy and safety of tenofovir DF vs stavudine in combination therapy in antiretroviral-naive patients: a 3-year randomized trial. JAMA 292: 191-201.

94. Brown TT, McComsey GA, King MS, Qaqish RB, Bernstein BM, et al. (2009) Loss of bone mineral density after antiretroviral therapy initiation, independent of antiretroviral regimen. J Acquir Immune Defic Syndr 51: 554-561.

95. Duvivier C, Kolta S, Assoumou L, Ghosn J, Rozenberg S, et al. (2009) Greate decrease in bone mineral density with protease inhibitor regimens compared with nonnucleoside reverse transcriptase inhibitor regimens in HIV-1 infected naive patients. AIDS 23: 817-824.

96. Hendricks KM, Mwamburi DM, Newby PK, Wanke CA (2008) Dietary patterns and health and nutrition outcomes in men living with HIV infection. Am J Clin Nutr 88: 1584-1592.

97. Sharma TS, Kinnamon DD, Duggan C, Weinberg GA, Furuta L, et al. (2008) Changes in macronutrient intake among HIV-infected children between 1995 and 2004. Am J Clin Nutr 88: 384-391.

98. Parakh A, Dubey AP, Kumar A, Maheshwari A (2009) Lipodystrophy and metabolic complications of highly active antiretroviral therapy. Indian J Pediat 76: 1017-1021.

99. Rodriguez de la Concepcion ML, Yubero P, Domingo JC, Iglesias R, Domingo $\mathrm{P}$, et al. (2005) Reverse transcriptase inhibitors alter uncoupling protein-1 and mitochondrial biogenesis in brown adipocytes. Antivir Ther 10: 515-526.

100. Caron-Debarle M, Boccara F, Lagathu C, Antoine B, Cervera P, et al. (2010) Adipose tissue as a target of HIV-1 antiretroviral drugs. Potential consequences on metabolic regulations. Curr Pharm Des 16: 3352-3360.

101.Lipshultz SE, Colan SD, Gelber RD, Perez-Atayde AR, Sallan SE, et al. (1991) 
Citation: Mas CM, Miller TL, Cordero C, Dauphin D, White MB, et al. (2011) The Effects of Fetal and Childhood Exposure to Antiretroviral Agents. J AIDS Clinic Res S2:001. doi:10.4172/2155-6113.S2-001

Late cardiac effects of doxorubicin therapy for acute lymphoblastic leukemia in childhood. N Engl J Med 324: 808-815.

102. Lipshultz SE (1995) Female sex and higher drug dose as risk factors for late cardiotoxic effects of doxorubicin therapy for childhood cancer. N Engl J Med 332: $1738-1744$

103. Lipshultz SE, Lipsitz SR, Sallan SE, Dalton VM, Mone SM, et al. (2005) Chronic progressive cardiac dysfunction years after doxorubicin therapy for childhood acute lymphoblastic leukemia. J Clin Oncol 23: 2629-2636.

104.Lipshultz SE, Easley KA, Orav EJ, Kaplan S, Starc TJ, et al. (2000) Cardiac dysfunction and mortality in HIV-infected children: The Prospective $\mathrm{P}^{2} \mathrm{C}^{2}$ HIV Multicenter Study. Pediatric Pulmonary and Cardiac Complications of Vertically Transmitted HIV Infection $\left(\mathrm{P}^{2} \mathrm{C}^{2} \mathrm{HIV}\right)$ Study Group. Circulation 102: 1542-1548.

105. Moodley D, Moodley J, Coovadia H, Gray G, Mclntyre J, et al. (2003) A multicenter randomized controlled trial of nevirapine versus a combination of zidovudine and lamivudine to reduce intrapartum and early postpartum mother-to-child transmission of human immunodeficiency virus type 1 . J Infect Dis 187: 725-735

106. Lallemant M, Jourdain G, Le Coeur S, Mary JY, Ngo-Giang-Huong N, et al. (2004) Single-dose perinatal nevirapine plus standard zidovudine to prevent mother-to-child transmission of HIV-1 in Thailand. N Engl J Med 351: 217-228.

107.Omer SB (2011) Twelve-month follow-up of Six Week Extended Dose Nevirapine randomized controlled trials: differential impact of extended-dose nevirapine on mother-to-child transmission and infant death by maternal CD4 cell count. AIDS 25: 767-776.

108. Noguera A, Fortuny C, Munoz-Almagro C, Sanchez E, Vilaseca MA, et al. (2004) Hyperlactatemia in human immunodeficiency virus-uninfected infants who are exposed to antiretrovirals. Pediatrics 114: e598-603.
109. Ekouevi DK, Toure R, Becquet R, Viho I, Sakarovitch C, et al. (2006) Serum lactate levels in infants exposed peripartum to antiretroviral agents to prevent mother-to-child transmission of HIV: Agence Nationale de Recherches Sur le SIDA et les Hepatites Virales 1209 study, Abidjan, Ivory Coast. Pediatrics 118 e1071-1077.

110. P, Chesaux JJ, Buchwalder PA, Biollaz J, Micheli JL (1998) Severe transient neonatal lactic acidosis during prophylactic zidovudine treatment. Intensive Care Med 24: 247-250.

11. U.S. State Department. Prevention: Direct FY2010 Prevention of Motherto-Child Transmission Program Results. Annual Report to Congress on the President's Emergency Plan for AIDS Relief.

112. El-Sadr WM, Hoos D (2008) The President's Emergency Plan for AIDS Relief-is the emergency over? N Engl J Med 359: 553-555.

113. Ciaranello AL, Seage GR, $3^{\text {rd }}$, Freedberg KA, Weinstein MC, Lockman S, et al. (2008) Antiretroviral drugs for preventing mother-to-child transmission of HIV in sub-Saharan Africa: balancing efficacy and infant toxicity. AIDS 22: 2359-2369.

114. Wogan GN (2007) Does perinatal antiretroviral therapy create an iatrogenic cancer risk? Environmental and molecular mutagenesis 48: 210-214.

115. Poirier MC, Olivero OA, Walker DM, Walker VE (2004) Perinatal genotoxicity and carcinogenicity of anti-retroviral nucleoside analog drugs. Toxicol Appl Pharmacol 199: 151-161.

116. Panel on Treatment of HIV-Infected Pregnant Women and Prevention of Perinatal Transmission. Recommendations for Use of Antiretroviral Drugs in Pregnant HIV1-Infected Women for Maternal Health and Interventions to Reduce Perinatal HIV Transmission in the United States. May 24, 2010; pp 1-117.

117. Lipshultz SE, Scully RE, Lipsitz SR, Sallan SE, Silverman LB, et al. (2010) Assessment of dexrazoxane as a cardioprotectant in doxorubicin-treated children with high-risk acute lymphoblastic leukaemia: long-term follow-up of a prospective, randomised, multicentre trial. Lancet Oncol 11: 950-961.
This article was originally published in a special issue, Pharmacology of Antiretroviral Agents: HIV handled by Editor(s). Dr. Di Wu, The Children's Hospital of Philadelphia, USA 